\title{
Minimally invasive esophagectomy in a 6-year-old girl for the sequelae of corrosive esophagitis
}

\author{
Jacqueline Majors, MD, ${ }^{\mathrm{a}}$ Ying Zhuge, MD, ${ }^{\mathrm{b}}$ James W. Eubanks III, MD, ${ }^{\mathrm{b}}$ and Benny Weksler, MD, MBA, ${ }^{\mathrm{a}}$ \\ Memphis, Tenn
}

\footnotetext{
From the Divisions of ${ }^{\mathrm{a}}$ Thoracic Surgery and ${ }^{\mathrm{b}}$ Pediatric Surgery, Department of Surgery, University of Tennessee Health Science Center, Memphis, Tenn.

Disclosures: Authors have nothing to disclose with regard to commercial support.

Received for publication March 17, 2016; revisions received June 7, 2016; accepted for publication June 10, 2016; available ahead of print July 9, 2016.

Address for reprints: Benny Weksler, MD, MBA, Division of Thoracic Surgery, Department of Surgery, University of Tennessee Health Science Center, 1325 Eastmoreland Ave, Ste 410, Memphis, TN 38104 (E-mail: bweksler@uthsc.edu).

J Thorac Cardiovasc Surg 2016;152:e115-6

$0022-5223 / \$ 36.00$

Copyright (C) 2016 by The American Association for Thoracic Surgery

http://dx.doi.org/10.1016/j.jtcvs.2016.06.011
}

Esophageal replacement in children is most commonly indicated for esophageal strictures that develop after a caustic ingestion and prohibit normal swallowing despite repeated dilations. Esophagectomy in children, typically performed using an open procedure, can be technically difficult if the esophagus is adhered to the aorta or airway. ${ }^{1}$ In adults, minimally invasive esophagectomy (MIE) can be performed with low mortality and morbidity. ${ }^{2}$ Here, we describe the case of a 6-year-old girl who underwent thoracoscopic and laparoscopic MIE.

\section{CLINICAL SUMMARY}

A 6-year-old girl required monthly serial dilations for a long midesophageal stricture after ingesting cleaner $(\mathrm{pH}$ 13) at age 3 years. All of her thoracic esophagus was strictured, with the most significant stricture at the level of the inferior pulmonary vein (Figure 1). Her proximal esophagus was dilated with signs of fibrosis. Five months after the ingestion, an esophageal perforation secondary to dilation was repaired via left thoracotomy. She underwent a laparoscopic Nissen fundoplication at age 5 years because acid reflux was thought to contribute to her recurrent strictures; however, over the next year, the duration of symptom relief after each dilation decreased. When we offered MIE, the patient was $128 \mathrm{~cm}$ tall and weighed $22 \mathrm{~kg}$.

We isolated the left lung for the thoracic portion of the procedure by inserting a $5-\mathrm{mm}$ endotracheal tube into the left main stem bronchus. We placed thoracoscopic ports in the same locations previously described for adults, ${ }^{3}$ but used only 5-mm ports. We then used 5-mm instruments and optics throughout the MIE. The esophagus had significant fibrous adhesions to the mediastinum, aorta, and airway. After dividing the azygos vein, we got around the esophagus below the inferior pulmonary vein and encircled it with a Penrose drain to facilitate dissection from the all ports.

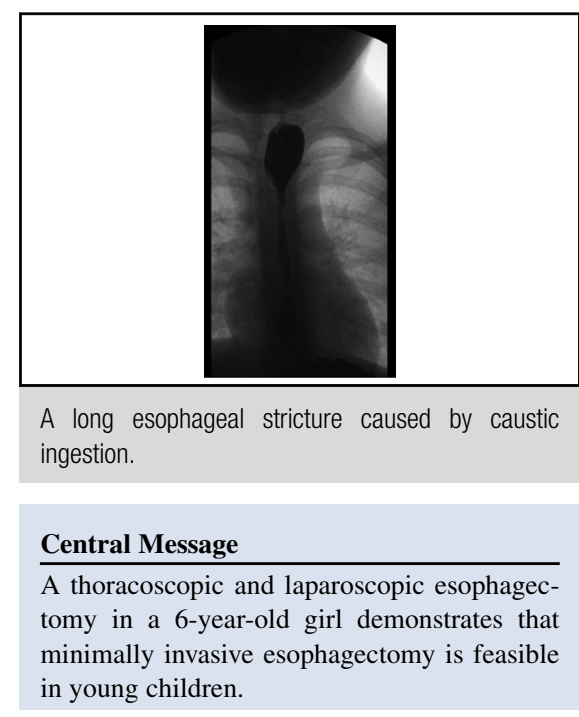

See Editorial Commentary page e117.

hiatus to the thoracic inlet. To protect the airway, aorta, and thoracic duct, we kept our plane of dissection very close to the esophagus and took great care not to extend the dissection laterally. We placed a chest tube before closing

With the patient supine, we positioned 4 5-mm abdominal ports, as in a Nissen fundoplication, with the camera port in the umbilicus. We mobilized the stomach by dividing the short gastric vessels and retrogastric attachments, taking care to preserve the right gastroepiploic artery, and divided the left gastric artery. Using a cervical incision, we mobilized and divided the esophagus.

We brought the stomach and esophagus through a $3-\mathrm{cm}$ minilaparotomy and removed the specimen, including the fundoplication. We crafted a narrow, $3-\mathrm{cm}$ gastric tube extracorporally using a 30-mm linear stapler and performed a Heineke-Mikulicz pyloroplasty. This differed from our technique in adults. The child's abdominal cavity was small, and using the bulky stapler intracorporeally would have been cumbersome. We did not believe that the $3-\mathrm{cm}$ midline incision had significant shortcomings. We pulled the gastric tube through the posterior mediastinum and created an end-to-end, single-layer, hand-sewn cervical anastomosis using 4-0 polydiaxanone sutures. Additionally, we did not place a feeding jejunostomy tube. 


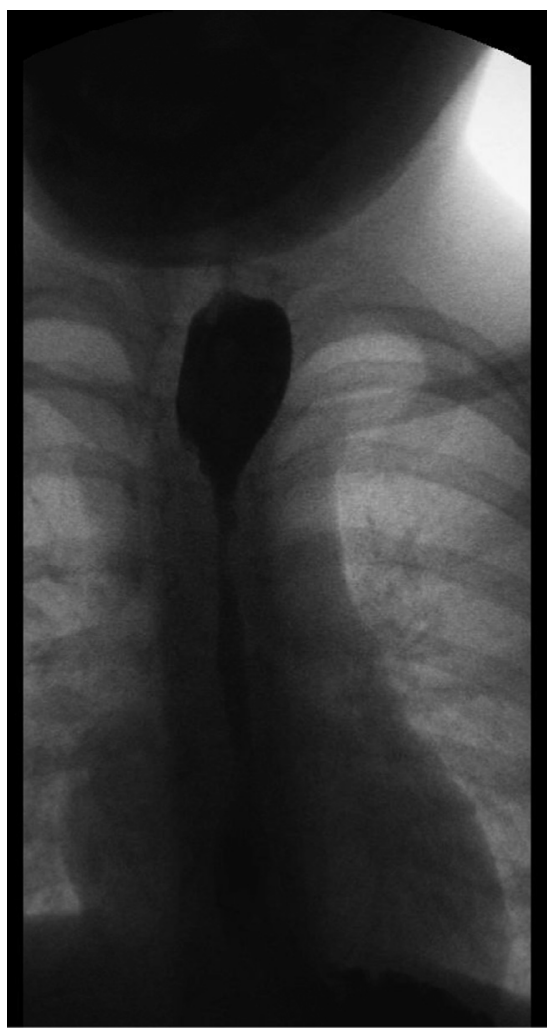

FIGURE 1. Barium esophagram of a long esophageal stricture from corrosive injury.

The postoperative course was uncomplicated, and there was no evidence of anastomotic leak (Figure 2). Postoperative pain was managed with intermittent intravenous narcotics. On postoperative day 8 , the child was discharged. She required 3 dilations of a cervical anastomotic stricture during the first year after MIE and currently is tolerating a regular diet.

\section{DISCUSSION}

To our knowledge, this is the youngest patient to undergo a thoracoscopic and laparoscopic esophagectomy. An MIE in a 17-year-old patient and a hybrid esophagectomy (thoracoscopy with laparotomy) in 2 children were previously reported. ${ }^{4,5}$ Esophageal replacement should be considered for treatment of caustic esophageal injury in children when symptom relief after dilation is brief. Esophageal perforation is a risk during each dilation and can lead to mediastinitis and death. The risk of malignant transformation is also an important consideration given the long life expectancy of most children.

We do not see disadvantages in attempting MIE in children. Blunt dissection of the esophagus during laparotomy can cause injury to mediastinal structures when there is marked fibrosis, and disruption of vessels branching from the aorta causes intrathoracic bleeding in $4 \%$ to $20 \%$ of

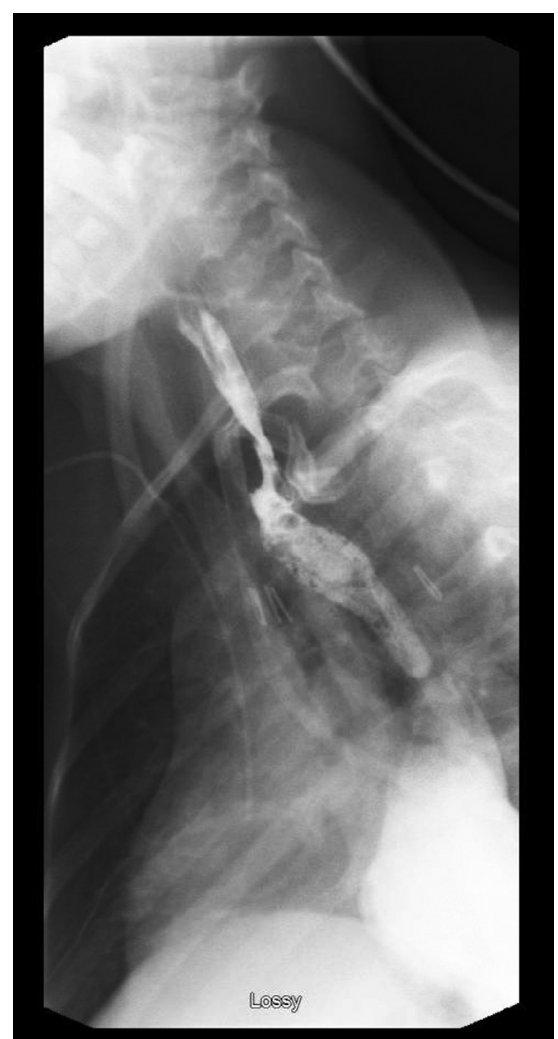

FIGURE 2. Barium esophagram 6 days after esophagectomy.

cases. ${ }^{5,6}$ In contrast, MIE may offer better visualization and more precise dissection of a fibrosed mediastinum, resulting in fewer intraoperative injuries. The availability of 3-mm instruments and optics may allow MIE in even smaller children. A surgeon experienced in adult MIE is an important member of the surgical team, because most pediatric surgeons do not have sufficient expertise.

\section{CONCLUSIONS}

MIE in young children is feasible and may decrease complications in children requiring esophagectomy.

\section{References}

1. Hamza AF, Abdelhay S, Sherif H, Hasan T, Soliman H, Kabesh A, et al. Caustic esophageal strictures in children: 30 years' experience. J Pediatr Surg. 2003;38: 828-33.

2. Luketich JD, Pennathur A, Awais O, Levy RM, Keeley S, Shende M, et al. Outcomes after minimally invasive esophagectomy: review of over 1000 patients. Ann Surg. 2012;256:95-103.

3. Levy RM, Trivedi D, Luketich JD. Minimally invasive esophagectomy. Surg Clin North Am. 2012;92:1265-85.

4. Nwomeh BC, Luketich JD, Kane TD. Minimally invasive esophagectomy for caustic esophageal stricture in children. J Pediatr Surg. 2004;39:e1-6.

5. Cury EK, Schraibman V, De Vasconcelos Macedo AL, Echenique LS. Thoracoscopic esophagectomy in children. J Pediatr Surg. 2001;36:E17.

6. Esteves E, Sousa-Filho HB, Watanabe S, Silva JF, Neto EC, da Costa AL. Laparoscopically assisted esophagectomy and colon interposition for esophageal replacement in children: preliminary results of a novel technique. J Pediatr Surg. 2010;45:1053-60. 